\title{
Prognostic value of preoperative lymphocyte- to-monocyte ratio in pancreatic adenocarcinoma
}

This article was published in the following Dove Press journal:

OncoTargets and Therapy

I March 2016

Number of times this article has been viewed

\section{Guang-Jun Li' \\ Hong-Wei $\mathrm{Xu}^{\prime}$ \\ Juan-Juan $\mathrm{Ji}^{2}$ \\ Fang Yang ${ }^{2}$ \\ Bao-Qin Gao'}

'First Department of General Surgery, ${ }^{2}$ Department of Gastroenterology,

First Affiliated Hospital of Xin-Xiang Medical University, Henan, People's

Republic of China
Correspondence: Juan-Juan Ji Department of Gastroenterology, First Affiliated Hospital of Xin-Xiang Medical University, 88 jiankang Road,

Weihui, Henan 463000, People's

Republic of China

Tel/fax +863734402120

Email yangfang880@sina.cn
Background: Inflammation and immunity have an important role in the development of cancer. The lymphocyte-to-monocyte ratio (LMR) has been shown to be of prognostic value in several malignant forms. The purpose of this study was to analyze the prognostic significance of preoperative LMR in post-curative resection of pancreatic adenocarcinoma.

Methods: A total of 144 patients with primary pancreatic adenocarcinoma who underwent curative operation were enrolled in this retrospective study. The correlation between preoperative LMR and survival was analyzed using Kaplan-Meier curves and multivariate Cox regression analyses.

Results: In the univariate analysis, an elevated preoperative LMR was significantly associated with an increased overall survival (OS) (19 months vs 12 months, $P=0.000$ ), and this result remained significant in the multivariate analysis (hazard ratio [HR]: $0.148 ; 95 \%$ confidence interval $[\mathrm{CI}]$ : $0.085-0.252 ; P=0.000)$. Furthermore, patients with high LMR also had higher median recurrence-free survival (RFS) than patients with low LMR in univariate (18 months vs 10 months, $P=0.000$ ) and multivariate analyses (HR: $0.148 ; 95 \% \mathrm{CI}$ : $0.085-0.252 ; P=0.000$ ). Subgroup analyses showed that both patients with stage III cancer and patients with stage I+II cancer can obtain OS and RFS benefits from high LMR.

Conclusion: LMR can be considered as an independent prognostic biomarker for operable pancreatic adenocarcinoma.

Keywords: lymphocyte to monocyte ratio, survival, pancreatic adenocarcinoma

\section{Introduction}

In People's Republic of China, the morbidity and mortality of pancreatic adenocarcinoma show an increasing trend due to changes in dietary composition and habits, and pancreatic adenocarcinoma has been ranked as the seventh most common cancer and the ninth leading cause of cancer-related deaths. ${ }^{1}$ Although currently there are several conventional and emerging treatment options available for pancreatic adenocarcinoma, surgery remains the main treatment approach, but is possible for only $20 \%$ of localized diseases. ${ }^{2}$ Moreover, patients who underwent curative resection continue to suffer from high rates of perioperative morbidity. ${ }^{3,4}$ Classification of pancreatic adenocarcinoma patients can help to predict survival and thus aid in providing individualized therapies that can improve clinical outcomes; therefore, the importance of prognostic and predictive biomarkers has been increasingly recognized. ${ }^{5}$ However, biomarkers actually utilized in clinical practice are currently limited to clinicopathological characteristics such as the histological stage, pathological type, resection margins, or tumor-node-metastasis (TNM) stage, which can be evaluated only through postoperative histological studies and findings during surgery. ${ }^{6-8}$ Therefore, new biomarkers that are inexpensive and technically feasible are required. (c)
hereby accept the Terms. Non-commercial uses of the work are permitted without any further permission from Dove Medical Press Limited, provided the work is properly attributed. For permission for commercial use of this work, please see paragraphs 4.2 and 5 of our Terms (https://www.dovepress.com/terms.php). 
It has been confirmed that inflammation plays an important role in the development and therapeutic response of many malignant tumors. ${ }^{9}$ Inflammatory-related cells can produce proangiogenic factors and inflammatory mediators, and thus generate a favorable cancer-related inflammatory microenvironment that promotes vascular invasion and suppression of the host immune system. ${ }^{10-12}$ Alternatively, tumors can secrete several cytokines that influence the blood cells associated with inflammation and immunity, including neutrophils, lymphocytes, monocytes, and blood platelets. ${ }^{13,14}$

Several inflammatory response related biomarkers have potential prognostic significance in patients with various types of malignancies, such as the neutrophilto-lymphocyte ratio, platelet-to-lymphocyte ratio, and lymphocyte-to-monocyte ratio (LMR). ${ }^{15-17}$ Fujiwara et al analyzed 111 patients who underwent pancreatic resection for pancreatic carcinoma and reported that the prognosis and overall survival of patients with low postoperative peripheral LMR was significantly poorer than those of patients with high postoperative peripheral LMR. ${ }^{18}$ However, there are still no reports concerning the association between preoperative LMR and survival in patients with resected pancreatic adenocarcinoma. In this study, we aimed to assess the prognostic significance of preoperative LMR in pancreatic adenocarcinoma patients who underwent curative surgery.

\section{Materials and methods Patients}

A total of 144 patients with primary pancreatic adenocarcinoma and who had undergone curative resection at the First Department of General Surgery in the First Affiliated Hospital of Xin-Xiang Medical University between June 1, 2012 and June 1, 2014 were enrolled in this study. Inclusion criteria were histologically confirmed pancreatic adenocarcinoma, $>18$ years of age, and life expectancy $>6$ months. The exclusion criteria were acute and severe preoperative medical conditions and adjuvant treatments, such as systemic infection, autoimmune diseases or inflammation, and chemotherapy. Medical information of all patients was collected from the clinical records by one surgeon and checked by another surgeon, including sex, age, American Society of Anesthesiologists (ASA) score, CA19-9, tumor site, tumor size, T stage, lymph node status, TNM, and pathological differentiation. Histopathological and clinic staging were evaluated through postoperative histopathological examination and clinical assessment by the Union for International Cancer Control
TNM classification, respectively. Routine blood test was carried out on the day before surgery to obtain absolute lymphocyte and monocyte counts. LMR was calculated by using the equation: LMR = absolute lymphocyte count/ absolute monocyte ratio.

\section{Follow-up}

All patients were followed up in regular style through outpatient visit, including physical and laboratory examinations CA19-9 was evaluated every 3 months for the first 2 years, every 6 months for the next 3 years, and once annually thereafter. Enhanced abdominal computed tomography (CT) or magnetic resonance imaging (MRI) scans were generally obtained for every 12 months. Clinical follow-up lasted from the date of surgery to either the time of death or June 2015. This study was approved by the Ethics Committee of the First Affiliated Hospital of Xin-Xiang Medical University. Written informed consent was obtained from all the individual participants.

\section{Statistical analysis}

Statistical analyses were performed by SPSS 21.0 (IBM Corporation, Armonk, NY, USA). $P<0.05$ (two-sided) was considered statistically significant. The optimal cutoff values for the LMR were determined through receiver operating characteristic curve analysis. OS was accurately defined as the duration from date of surgery to death, while recurrencefree survival (RFS) was calculated as the time from diagnosis to tumor recurrence. The $\chi^{2}$ test or Fisher's exact test was used to analyze the association between qualitative variables and LMR, while quantitative values were analyzed by independent Student's $t$-test. The OS, RFS, and survival curve were studied in Kaplan-Meier analyses by using the log-rank test. The Cox regression model was used to assess the hazard ratio (HR) and multivariate analysis.

\section{Results}

Baseline clinicopathological characteristics are shown in Table 1. A total of 144 patients with primary localized pancreatic adenocarcinoma were included in our study, and among them 77 were males and 67 females, with an average age of $62 \pm 2.8$ years. Eighty-nine patients were diagnosed with pancreatic head adenocarcinoma, while tumors in 55 patients were located at pancreatic body or tail. According to the TNM staging methods, 45 patients were diagnosed with stage I or II tumor and 99 with stage III tumor. Based on pathological analysis, we found that 76 patients suffered from well/moderately differentiated adenocarcinoma, whereas 68 patients presented with poorly differentiated adenocarcinoma. 
Table I Correlation between the percentage of LMR and clinicopathological characteristics

\begin{tabular}{|c|c|c|c|}
\hline \multirow[t]{2}{*}{ Characteristics } & \multicolumn{2}{|l|}{ LMR } & \multirow[t]{2}{*}{$P$-value } \\
\hline & $\geq 2.8(n=68)$ & $<2.8(n=76)$ & \\
\hline Age (years) & & & 0.504 \\
\hline$\geq 60$ & 36 & 36 & \\
\hline$<60$ & 32 & 40 & \\
\hline Sex & & & 0.593 \\
\hline Male & 36 & 46 & \\
\hline Female & 32 & 30 & \\
\hline ASA score & & & 0.244 \\
\hline $\mathrm{I}+2$ & 51 & 63 & \\
\hline 3 & 17 & 13 & \\
\hline CAI9-9 (U/mL) & & & 0.175 \\
\hline$\geq 200$ & 42 & 55 & \\
\hline$<200$ & 26 & 21 & \\
\hline WBC count (/L) & & & 0.573 \\
\hline$\geq 5 \times 10^{9}$ & 38 & 46 & \\
\hline$<5 \times 10^{9}$ & 30 & 30 & \\
\hline Lymphocyte count (/L) & & & 0.000 \\
\hline$\geq 1.3 \times 10^{9}$ & 57 & 12 & \\
\hline$<1.3 \times 10^{9}$ & 11 & 64 & \\
\hline Monocyte count (/L) & & & 0.000 \\
\hline$\geq 0.4 \times 10^{9}$ & 22 & 62 & \\
\hline$<0.4 \times 10^{9}$ & 46 & 14 & \\
\hline Tumor site & & & 0.983 \\
\hline Head & 50 & 56 & \\
\hline Body/tail & 18 & 20 & \\
\hline Tumor size (cm) & & & 0.247 \\
\hline$\geq 3.0$ & 14 & 22 & \\
\hline$<3$ & 54 & 54 & \\
\hline Tumor invasion depth & & & $0.88 I$ \\
\hline $\mathrm{TI}+\mathrm{T} 2$ & 11 & 13 & \\
\hline $\mathrm{T} 3+\mathrm{T} 4$ & 57 & 63 & \\
\hline Lymph node involvement & & & 0.193 \\
\hline No & 32 & 44 & \\
\hline $\mathrm{NI}$ & 36 & 32 & \\
\hline TNM stage & & & $0.04 I$ \\
\hline $\mathrm{I}+\mathrm{II}$ & 42 & 34 & \\
\hline III & 26 & 42 & \\
\hline $\begin{array}{l}\text { Pathological } \\
\text { differentiation }\end{array}$ & & & 0.860 \\
\hline Well/moderate & 33 & 38 & \\
\hline Poor & 35 & 38 & \\
\hline
\end{tabular}

Abbreviations: ASA, American Society of Anesthesiologists; WBC, white blood cells; LMR, lymphocyte to monocyte ratio; TNM, tumor-node-metastasis.

Moreover, there was no statistically significant association between LMR and clinicopathological characteristics except the TNM stage.

\section{Prognostic significance of LMR for pancreatic adenocarcinoma}

The median LMR from all enrolled patients was 2.8 (range: $1.2-4.7)$. In the receiver operating characteristic curve analysis, the optimal cutoff levels for the LMR were 2.86 for OS and 2.58 for RFS. The area under the curve was 0.632 for OS and 0.569 for RFS (Figure 1). The median follow-up time was 14 months (range 6-40 months). There were significant associations between T stage, lymph node involvement, TNM stage, and LMR with OS and RFS (Tables 2 and 3).

At the end of this study, among 144 patients with pancreatic adenocarcinoma, 114 (79.2\%) developed tumor recurrence and $110(76.4 \%)$ died within the follow-up period. The tumor recurred in $70(93.3 \%)$ out of 75 patients with an LMR $<2.58$ and in $44(63.8 \%)$ out of 69 patients with an LMR $\geq 2.58$. Death occurred in $68(87.2 \%)$ out of 78 patients with an LMR $<2.86$ and in $42(63.6 \%)$ out of 66 patients with an $L M R \geq 2.86$. In univariate analyses, patients with an LMR $\geq 2.86$ in peripheral blood had a statistically significantly better postoperative prognosis than those with an LMR $<2.86$ in median OS (19 months vs 12 months, $P=0.000$ ) (Table 2, Figure 2). Furthermore, this result remained significant in the multivariate analysis (HR: $0.148 ; 95 \%$ confidence interval $[\mathrm{CI}]: 0.085-0.252 ; P=0.000$ ) (Table 2). When compared to the patients with low LMR $(<2.58)$, patients with high LMR $(\geq 2.58)$ also had higher median RFS in univariate (18 months vs 10 months, $P=0.000$ ) and multivariate analyses (HR: 0.152; 95\% CI: 0.092-0.250; $P=0.000$ ) (Table 3, Figure 3).

For locally resected advanced pancreatic adenocarcinoma (TNM stage III), patients with high LMR had a median OS of 18 months, whereas patients with low LMR had a median OS of 7 months $(P=0.000)$. Alternatively, high LMR was also predictive of higher median RFS in patients with stage III cancer ( 16 months vs 7 months, $P=0.000$ ). When compared with low LMR, high LMR was significantly associated with higher OS (24 months vs 15 months, $P=0.010$ ) as well as higher RFS (20 months vs 13 months, $P=0.003$ ) in patients with stage I and II cancer (Figure 3).

A multivariate analysis enrolled the sex of patients, ASA score, CA19-9, tumor size, histological differentiation type, TNM stage, and LMR into the COX regression model to identify independent prognostic factors for operable pancreatic adenocarcinoma since TNM stage is obtained from combining tumor invasion depth and lymph node involvements and LMR (calculated from lymphocyte and monocyte counts). The result showed that LMR (HR: 0.148; 95\% CI: $0.085-0.252 ; P<0.05$ ), TNM (HR: $5.631 ; 95 \%$ CI: $3.148-9.182 ; P<0.05$ ), and pathological differentiation (HR: 0.566 ; $95 \%$ CI: $0.402-0.932 ; P<0.05$ ) were the independent prognostic factors for OS of patients with pancreatic adenocarcinoma (Table 2). Otherwise, ASA score (HR: 2.297; 95\% CI: $1.286-4.103 ; P<0.05$ ), LMR (HR: $0.152 ; 95 \%$ CI: $0.092-0.250 ; P<0.05$ ), TNM (HR: 3.896; 95\% CI: $1.168-$ $9.283 ; P<0.05$ ), and pathological differentiation (HR: 0.599 ; 
A

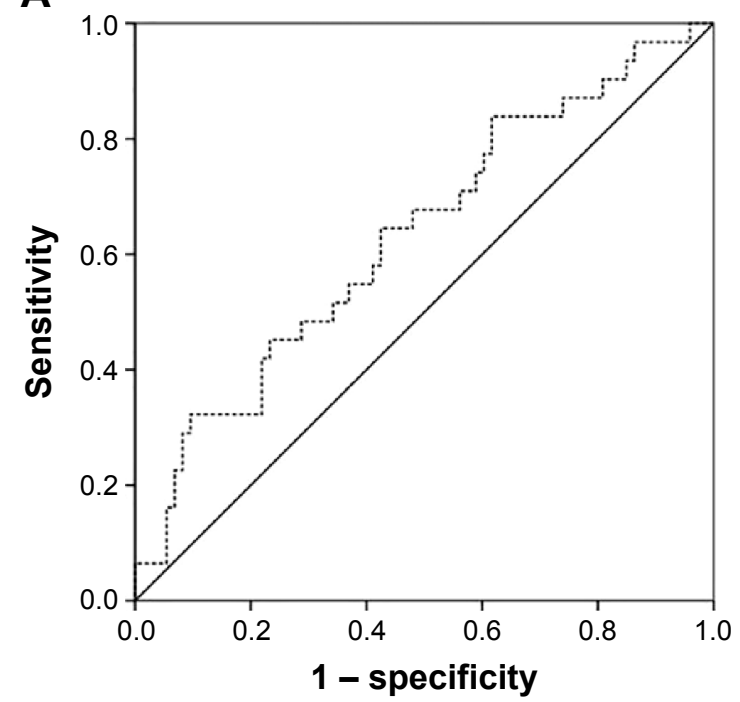

B

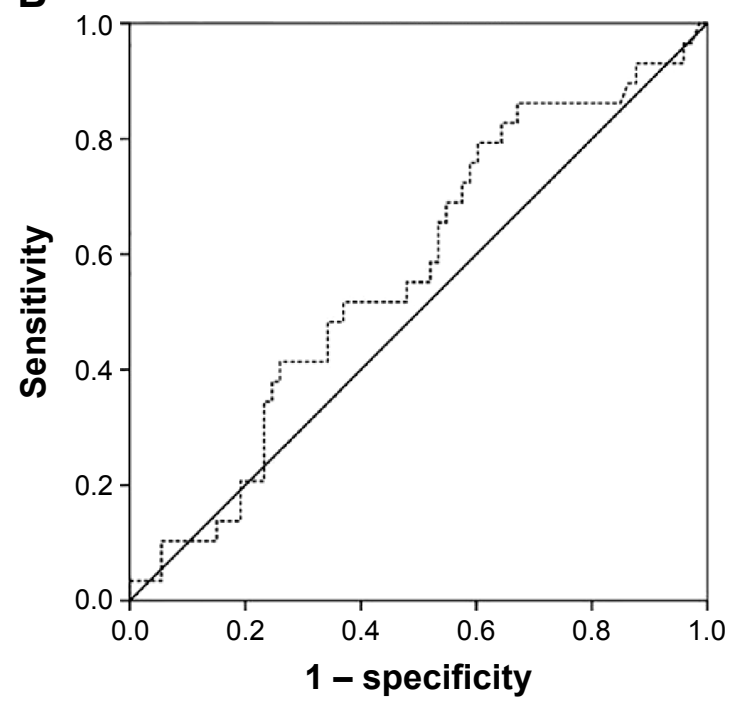

Figure I (A) ROC curve for OS, the area under the curve was 0.632 for LMR. (B) ROC curve for RFS, the area under the curve was 0.569 for LMR. Abbreviations: ROC, receiver-operator characteristic; OS, overall survival; LMR, leukocyte to monocyte ratio; RFS, recurrence-free survival.

Table 2 Univariate and multivariate analyses of the association of the prognostic characteristics with OS

\begin{tabular}{|c|c|c|c|c|c|c|}
\hline & \multicolumn{3}{|l|}{ Univariate } & \multicolumn{3}{|c|}{ Multivariate } \\
\hline & Patients (n) & MS (months) & $P$-value & HR & $95 \% \mathrm{Cl}$ & $P$-value \\
\hline Age (years) & & & 0.083 & & & \\
\hline$\geq 60$ & 72 & 14 & & & & \\
\hline$<60$ & 72 & 17 & & & & \\
\hline Sex & & & 0.534 & & & \\
\hline Male & 82 & 14 & & & & \\
\hline Female & 62 & 16 & & & & \\
\hline ASA score & & & 0.032 & & & \\
\hline $\mathrm{I}+2$ & 114 & 18 & & & & \\
\hline 3 & 30 & 12 & & & & \\
\hline CAI9-9 (U/mL) & & & 0.874 & & & \\
\hline$\geq 200$ & 97 & 14 & & & & \\
\hline$<200$ & 47 & 16 & & & & \\
\hline WBC count (/L) & & & 0.448 & & & \\
\hline$\geq 5 \times 10^{9}$ & 84 & 13 & & & & \\
\hline$<5 \times 10^{9}$ & 60 & 17 & & & & \\
\hline Lymphocyte count (/L) & & & 0.022 & & & \\
\hline$\geq 1.3 \times 10^{9}$ & 69 & 19 & & & & \\
\hline$<1.3 \times 10^{9}$ & 75 & 13 & & & & \\
\hline Monocyte count (/L) & & & $0.08 I$ & & & \\
\hline$\geq 0.4 \times 10^{9}$ & 84 & 12 & & & & \\
\hline$<0.4 \times 10^{9}$ & 60 & 18 & & & & \\
\hline Tumor location & & & 0.182 & & & \\
\hline Head & 106 & 16 & & & & \\
\hline Body/tail & 38 & 14 & & & & \\
\hline Tumor size $(\mathrm{cm})$ & & & 0.204 & & & \\
\hline$\geq 3.0$ & 36 & 14 & & & & \\
\hline$<3$ & 108 & 19 & & & & \\
\hline T stage & & & 0.005 & & & \\
\hline $\mathrm{TI}+\mathrm{T} 2$ & 24 & 22 & & & & \\
\hline $\mathrm{T} 3+\mathrm{T} 4$ & 120 & 14 & & & & \\
\hline
\end{tabular}


Table 2 (Continued)

\begin{tabular}{|c|c|c|c|c|c|c|}
\hline & \multicolumn{3}{|l|}{ Univariate } & \multicolumn{3}{|c|}{ Multivariate } \\
\hline & Patients (n) & MS (months) & $P$-value & HR & $95 \% \mathrm{Cl}$ & $P$-value \\
\hline Lymph node status & & & 0.001 & & & \\
\hline No & 76 & 18 & & & & \\
\hline $\mathrm{NI}$ & 68 & 13 & & & & \\
\hline TNM stage & & & 0.000 & 5.631 & $3.148-9.182$ & 0.000 \\
\hline I+II & 76 & 18 & & & & \\
\hline III & 68 & 13 & & & & \\
\hline Pathological differentiation & & & 0.005 & 0.566 & $0.402-0.932$ & 0.021 \\
\hline Well/moderate & 71 & 17 & & & & \\
\hline Poor & 73 & 13 & & & & \\
\hline LMR & & & 0.000 & 0.148 & $0.085-0.252$ & 0.000 \\
\hline$\geq 2.86$ & 34 & 19 & & & & \\
\hline$<2.86$ & 38 & 12 & & & & \\
\hline
\end{tabular}

Abbreviations: OS, overall survival; MS, median survival; ASA, American Society of Anesthesiologists; WBC, white blood cells; Cl, confidence interval; HR, hazard ratio; LMR, lymphocyte to monocyte ratio; TNM, tumor-node-metastasis.

Table 3 Univariate and multivariate analyses of the association of the prognostic characteristics with RFS

\begin{tabular}{|c|c|c|c|c|c|c|}
\hline & \multicolumn{3}{|l|}{ Univariate } & \multicolumn{3}{|c|}{ Multivariate } \\
\hline & Patients (n) & MS (months) & $P$-value & HR & $95 \% \mathrm{Cl}$ & $P$-value \\
\hline Age (years) & & & 0.093 & & & \\
\hline$\geq 60$ & 72 & 12 & & & & \\
\hline$<60$ & 72 & 15 & & & & \\
\hline Sex & & & 0.426 & & & \\
\hline Male & 82 & 13 & & & & \\
\hline Female & 62 & 14 & & & & \\
\hline ASA score & & & 0.023 & 2.297 & $1.286-4.103$ & 0.005 \\
\hline $\mathrm{I}+2$ & 114 & 12 & & & & \\
\hline 3 & 30 & 15 & & & & \\
\hline CAI9-9 (U/mL) & & & 0.584 & & & \\
\hline$\geq 200$ & 97 & 13 & & & & \\
\hline$<200$ & 47 & 15 & & & & \\
\hline WBC count (/L) & & & 0.662 & & & \\
\hline$\geq 5 \times 10^{9}$ & 84 & 15 & & & & \\
\hline$<5 \times 10^{9}$ & 60 & 12 & & & & \\
\hline Lymphocyte count (/L) & & & 0.021 & & & \\
\hline$\geq 1.3 \times 10^{9}$ & 69 & 16 & & & & \\
\hline$<1.3 \times 10^{9}$ & 75 & 12 & & & & \\
\hline Monocyte count (/L) & & & 0.042 & & & \\
\hline$\geq 0.4 \times 10^{9}$ & 84 & 12 & & & & \\
\hline$<0.4 \times 10^{9}$ & 60 & 15 & & & & \\
\hline Tumor location & & & 0.273 & & & \\
\hline Head & 106 & 14 & & & & \\
\hline Body/tail & 38 & 13 & & & & \\
\hline Tumor size $(\mathrm{cm})$ & & & 0.204 & & & \\
\hline$\geq 3.0$ & 36 & 13 & & & & \\
\hline$<3$ & 108 & 15 & & & & \\
\hline T stage & & & 0.014 & & & \\
\hline $\mathrm{TI}+\mathrm{T} 2$ & 24 & 14 & & & & \\
\hline $\mathrm{T} 3+\mathrm{T} 4$ & 120 & 13 & & & & \\
\hline Lymph node status & & & 0.004 & & & \\
\hline NO & 76 & 16 & & & & \\
\hline NI & 68 & 12 & & & & \\
\hline TNM stage & & & 0.001 & 3.896 & I.168-9.283 & 0.050 \\
\hline $\mathrm{I}+\mathrm{II}$ & 76 & 16 & & & & \\
\hline III & 68 & 12 & & & & \\
\hline
\end{tabular}


Table 3 (Continued)

\begin{tabular}{|c|c|c|c|c|c|c|}
\hline & \multicolumn{3}{|l|}{ Univariate } & \multicolumn{3}{|c|}{ Multivariate } \\
\hline & Patients (n) & MS (months) & $P$-value & HR & $95 \% \mathrm{Cl}$ & $P$-value \\
\hline Pathological differentiation & & & 0.008 & 0.599 & $0.393-0.912$ & 0.017 \\
\hline Well/moderate & 71 & 15 & & & & \\
\hline Poor & 73 & 12 & & & & \\
\hline LMR & & & 0.000 & 0.152 & $0.092-0.250$ & 0.000 \\
\hline$\geq 2.58$ & 34 & 18 & & & & \\
\hline$<2.58$ & 38 & 10 & & & & \\
\hline
\end{tabular}

Abbreviations: RFS, recurrence-free survival; MS, median survival; ASA, American Society of Anesthesiologists; WBC, white blood cells; Cl, confidence interval; HR, hazard ratio; LMR, lymphocyte to monocyte ratio; TNM, tumor-node-metastasis.

95\% CI: $0.393-0.912 ; P<0.05)$ were the independent prognostic factors for RFS of patients with pancreatic adenocarcinoma (Table 3).

\section{Discussion}

In this study, we analyzed a large cohort of patients who underwent curative resection for primary pancreatic adenocarcinoma and found a significant association of LMR with OS and RFS in univariate analysis. Furthermore, in the subgroup analyses, the association was also applied to both patients with advanced pancreatic adenocarcinoma and patients with early cancer. LMR is independent prognostic factor for pancreatic adenocarcinoma. Therefore, our study confirmed that preoperative LMR can be used to enable optimal risk stratification for individual patients prior to treatment and to predict post-curative resection prognosis for pancreatic adenocarcinoma.

Inflammation plays an important role in cancer progression and metastasis, which are also influenced by host immunity. ${ }^{19}$ Lymphocytes are the main components of the immune system and cellular basis of immunosurveillance and immunoediting, reflecting immune response against the tumor. ${ }^{20}$ Lymphocytopenia is also a significant characteristic in patients with advanced pancreatic cancer when vascular invasion, lymph node, or distant metastases are present, which has been found to be an independent prognostic factor for OS in pancreatic cancers. ${ }^{21-23}$

Tumor-infiltrating leukocytes, including neutrophils and monocytes, also have a crucial role in the development and progression of a tumor. ${ }^{24}$ The monocytes in peripheral blood include the dendritic cells and macrophages. ${ }^{25}$ Dendritic cells with regulatory function cause immunosuppression through activated $\mathrm{T}_{\text {reg }}$ cells in patients with malignant tumor while macrophages kill tumor cells. ${ }^{26,27}$ Several studies showed that increased preoperative peripheral blood monocyte count negatively correlated with survival in patients with malignancy. ${ }^{28,29}$

LMR, as an inflammation and immunity-related biomarker based on lymphocytes and monocytes, has been found to be a significant prognostic marker for several
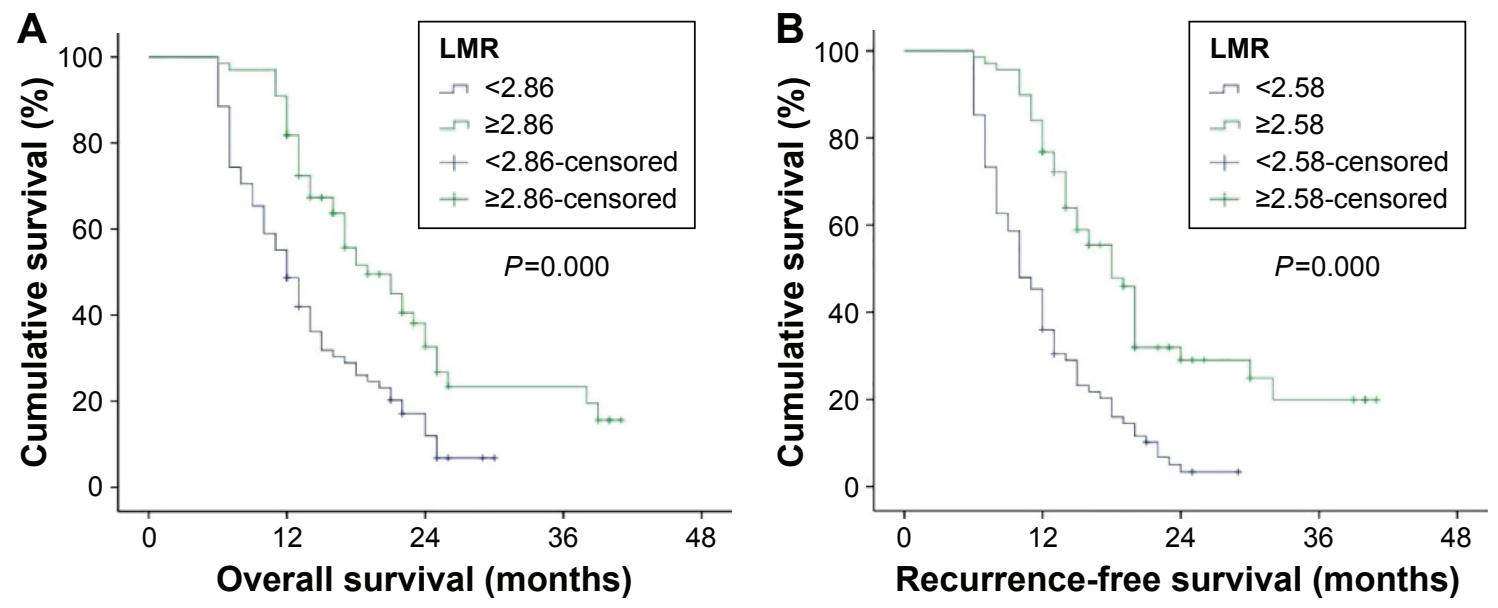

Figure 2 Kaplan-Meier estimates of survival.

Notes: (A) Shows the association between LMR and OS (median survival in LMR $\geq 2.86,19$ months; in LMR $<2.86,12$ months, $P=0.000$ ). (B) Shows the association between $L M R$ and RFS (median survival in $L M R \geq 2.58$, 18 months; in $L M R<2.58,10$ months, $P=0.000$ ).

Abbreviations: LMR, leukocyte to monocyte ratio; OS, overall survival; RFS, recurrence-free survival. 

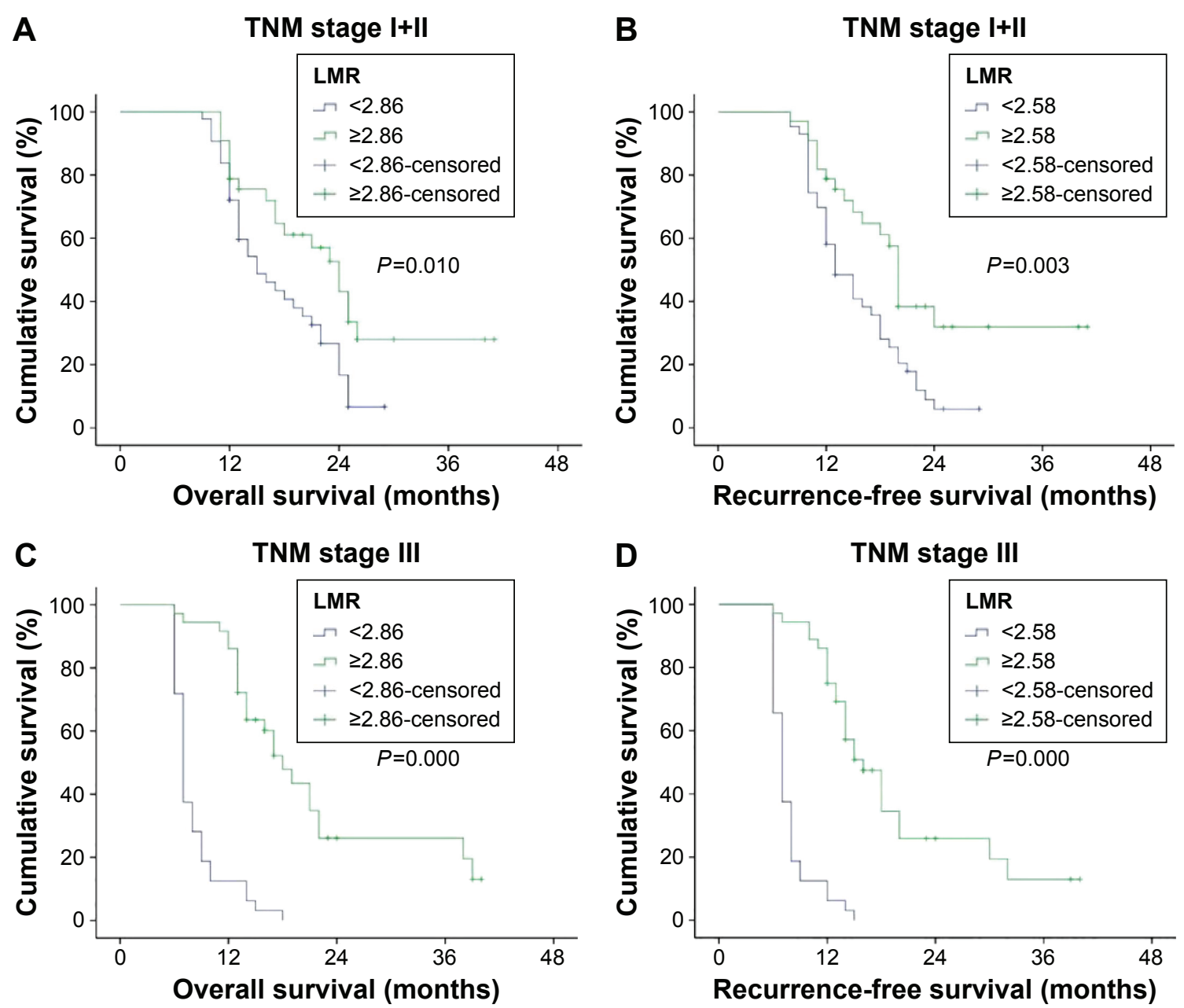

Figure 3 TNM stage wise survivability.

Notes: (A and B) Show that there is statistically significant correlation between LMR and OS and RFS of patients with early stage cancer. (C and D) Show that there is significant association between LMR and OS and RFS of patients with advanced cancer.

Abbreviations: TNM, tumor-node-metastasis; LMR, leukocyte to monocyte ratio; OS, overall survival; RFS, recurrence-free survival.

malignancies. ${ }^{30-32}$ Stotz et al analyzed 372 patients with stage II and III colon cancer and found that the LMR might be an independent prognostic marker for TTR (time to recurrence) in stage III patients. ${ }^{31}$ Chen et al evaluated the prognostic values of LMR in 485 patients with stage Ib1-IIa cervical cancer and found that decreased pretreatment LMR is associated with a poor prognosis in stage Ib1-IIa patients who undergo a radical operation. ${ }^{33}$ In the present study, we analyzed 144 patients who underwent curative operation for primary pancreatic adenocarcinoma, and found that LMR was not only an independent prognostic factor of primary pancreatic adenocarcinoma but also significantly related to TNM stage, which coincides with previous studies.

There were several limitations to this study that could have possibly influenced the results. One problem was retrospective design of the study and limited number of patients involved. A large-scale multicenter prospective study would be preferred to confirm our results and to exclude selection bias. Furthermore, the cutoff levels of LMR value used in our study may not be suitable for other studies. A meta-analysis including various LMR validation studies may be required to confirm the cutoff value for LMR.

In conclusion, LMR, as an easily and generally available, low price biomarker, could be considered as an independent prognostic factor for operable pancreatic adenocarcinoma.

\section{Disclosure}

The authors report no conflicts of interest in this work.

\section{References}

1. Chen W. Cancer statistics: updated cancer burden in China. Chin J Cancer Res. 2015;27(1):1.

2. Vincent A, Herman J, Schulick R, Hruban RH, Goggins M. Pancreatic cancer. Lancet. 2011;378(9791):607-620. 
3. Philip PA. Improving treatment of pancreatic cancer. Lancet Oncol. 2008; 9(1):7-8.

4. Katz MH, Wang H, Fleming JB, et al. Long-term survival after multidisciplinary management of resected pancreatic adenocarcinoma. Ann Surg Oncol. 2009;16(4):836-847.

5. McMillan DC. The systemic inflammation-based Glasgow Prognostic Score: a decade of experience in patients with cancer. Cancer Treat Rev. 2013;39(5):534-540.

6. Schwarz L, Katz MH. Diagnosis and management of borderline resectable pancreatic adenocarcinoma. Hematol Oncol Clin North Am. 2015;29(4):727-740.

7. Sharma G, Whang EE, Ruan DT, Ito H. Efficacy of neoadjuvant versus adjuvant therapy for resectable pancreatic adenocarcinoma: a decision analysis. Ann Surg Oncol. 2015;22(Suppl 3):1229-1237.

8. Martin RC II, Kwon D, Chalikonda S, et al. Treatment of 200 locally advanced (stage III) pancreatic adenocarcinoma patients with irreversible electroporation: safety and efficacy. Ann Surg. 2015;262(3):486-494.

9. Lu H, Ouyang W, Huang C. Inflammation, a key event in cancer development. Molecular Cancer Res. 2006;4(4):221-233.

10. Balkwill F, Mantovani A. Inflammation and cancer: back to Virchow? Lancet. 2001;357(9255):539-545.

11. Candido J, Hagemann T. Cancer-related inflammation. J Clin Immunol. 2013;33(Suppl 1):S79-S84.

12. Grivennikov SI, Greten FR, Karin M. Immunity, inflammation, and cancer. Cell. 2010;140(6):883-899.

13. Lippi G, Meschi T, Nouvenne A, Mattiuzzi C, Borghi L. Neutrophil gelatinase-associated lipocalin in cancer. Adv Clin Chem. 2014;64: 179-219.

14. Del Prete A, Allavena P, Santoro G, Fumarulo R, Corsi MM, Mantovani A. Molecular pathways in cancer-related inflammation. Biochem Med (Zagreb). 2011;21(3):264-275.

15. Jamieson NB, Denley SM, Logue J, et al. A prospective comparison of the prognostic value of tumor- and patient-related factors in patients undergoing potentially curative surgery for pancreatic ductal adenocarcinoma. Ann Surg Oncol. 2011;18(8):2318-2328.

16. Shirai Y, Shiba H, Sakamoto T, et al. Preoperative platelet to lymphocyte ratio predicts outcome of patients with pancreatic ductal adenocarcinoma after pancreatic resection. Surgery. 2015;158(2):360-365.

17. An X, Ding PR, Li YH, et al. Elevated neutrophil to lymphocyte ratio predicts survival in advanced pancreatic cancer. Biomarkers. 2010;15(6): 516-522.

18. Fujiwara Y, Misawa T, Shiba H, et al. Postoperative peripheral absolute blood lymphocyte-to-monocyte ratio predicts therapeutic outcome after pancreatic resection in patients with pancreatic adenocarcinoma. Anticancer Res. 2014;34(9):5163-5168.
19. Diakos CI, Charles KA, McMillan DC, Clarke SJ. Cancer-related inflammation and treatment effectiveness. Lancet Oncol. 2014;15(11): e493-e503.

20. Dunn GP, Old LJ, Schreiber RD. The immunobiology of cancer immunosurveillance and immunoediting. Immunity. 2004;21(2):137-148.

21. Romano F, Uggeri F, Crippa S, et al. Immunodeficiency in different histotypes of radically operable gastrointestinal cancers. J Exp Clin Cancer Res. 2004;23(2):195-200

22. von Bernstorff W, Voss M, Freichel S, et al. Systemic and local immunosuppression in pancreatic cancer patients. Clin Cancer Res. 2001; 7(Suppl 3):925s-932s.

23. Fogar P, Sperti C, Basso D, et al. Decreased total lymphocyte counts in pancreatic cancer: an index of adverse outcome. Pancreas. 2006;32(1): $22-28$.

24. Mantovani A, Allavena P, Sica A, Balkwill F. Cancer-related inflammation. Nature. 2008;454(7203):436-444.

25. Sica A, Allavena P, Mantovani A. Cancer related inflammation: the macrophage connection. Cancer Lett. 2008;267(2):204-215.

26. Takahashi T, Kuniyasu Y, Toda M, et al. Immunologic self-tolerance maintained by CD25+CD4+ naturally anergic and suppressive $\mathrm{T}$ cells: induction of autoimmune disease by breaking their anergic/suppressive state. Int Immunol. 1998;10(12):1969-1980.

27. Fidler IJ, Schroit AJ. Recognition and destruction of neoplastic cells by activated macrophages: discrimination of altered self. Biochim Biophys Acta. 1988;948(2):151-173.

28. Sasaki A, Kai S, Endo Y, et al. Prognostic value of preoperative peripheral blood monocyte count in patients with colorectal liver metastasis after liver resection. J Gastrointest Surg. 2007;11(5):596-602.

29. Sasaki A, Iwashita Y, Shibata K, Matsumoto T, Ohta M, Kitano S. Prognostic value of preoperative peripheral blood monocyte count in patients with hepatocellular carcinoma. Surgery. 2006;139(6):755-764.

30. Zhang GM, Zhu Y, Luo L, et al. Preoperative lymphocyte-monocyte and platelet-lymphocyte ratios as predictors of overall survival in patients with bladder cancer undergoing radical cystectomy. Tumour Biol. 2015;36(11):8537-8543.

31. Stotz M, Pichler M, Absenger G, et al. The preoperative lymphocyte to monocyte ratio predicts clinical outcome in patients with stage III colon cancer. Br J Cancer. 2014;110(2):435-440.

32. Zhou X, Du Y, Xu J, et al. The preoperative lymphocyte to monocyte ratio predicts clinical outcomes in patients with stage II/III gastric cancer. Tumour Biol. 2014;35(11):11659-11666.

33. Chen L, Zhang F, Sheng XG, Zhang SQ. Decreased pretreatment lymphocyte/monocyte ratio is associated with poor prognosis in stage Ib1-IIa cervical cancer patients who undergo radical surgery. Onco Targets Ther. 2015;8:1355-1362.
OncoTargets and Therapy

\section{Publish your work in this journal}

OncoTargets and Therapy is an international, peer-reviewed, open access journal focusing on the pathological basis of all cancers, potential targets for therapy and treatment protocols employed to improve the management of cancer patients. The journal also focuses on the impact of management programs and new therapeutic agents and protocols on
Dovepress

patient perspectives such as quality of life, adherence and satisfaction The manuscript management system is completely online and includes a very quick and fair peer-review system, which is all easy to use. Visit http://www.dovepress.com/testimonials.php to read real quotes from published authors. 